C O N T R I B U I Ç Ã O E S P E C I A L

\title{
ASSOCIATIVISMO DE MORADORES DE FAVELAS CARIOCAS E CRIMINALIZAÇÃO
}

Associativism of Rio de Janeiro slum's residents and criminalization Asociativismo de habitantes de favelas cariocas y criminalización

\author{
LIA DE MATTOS ROCHA ${ }^{*}$
}

\footnotetext{
' Universidade do Estado do Rio de Janeiro (UERJ), Rio de Janeiro - RJ, Brasil.

* Professora do Departamento de Sociologia e do Programa de Pós-Graduação em Ciências Sociais da Universidade do Estado do Rio de Janeiro e Coordenadora do CIDADES - Núcleo de Pesquisa Urbana. (liarocha08@gmail.com)

Artigo recebido em $1^{\circ}$ de junho de 2018 e aceito para publicação em 10 de setembro de 2018.
} 


\title{
RESUMO
}

Neste artigo, articulo diversos momentos de trabalho de campo qualitativo em favelas cariocas para investigar as dinâmicas de negociação entre os dirigentes de associações dessas localidades e os agentes civis e militares do poder público, notadamente durante o Programa de "Pacificação" de Favelas, iniciado em 2008. Argumento que 0 silenciamento e o rebaixamento da crítica dos moradores são operados através da desqualificação desses, e nessa operação, a criminalização é um elemento fundamental. Concluo discutindo como silenciar, disciplinar e criminalizar compõem o repertório do governo dos pobres nas periferias urbanas e seus efeitos para a democracia.

\section{PALAVRAS-CHAVE: Favela; Associativisma, Criminalizaçãa, Segregaçãa Militarização.}

\begin{abstract}
In this article, I associate several moments of qualitative fieldwork in Rio de Janeiro's slums to investigate the negotiation dynamics between the leaders of associations from these localities and the civil and military agents of the public authority, notably during the "Program of Pacification of the Slums", initiated in 2008. I argue that the silencing and demotion of the critics of the residents are operated through their disqualification and, in this operation, criminalization is an important element. I conclude the article discussing how the act of silencing, disciplining and criminalizing compose the repertoire of poor people's government in the urban peripheries and their effects on democracy.
\end{abstract}

\section{KeYwORDS: Sums, Assodiativism Giminalization, Segregation; Militarization}

\section{RESUMEN}

En este artículo se analizan diversos momentos de trabajo de campo cualitativo en favelas cariocas para investigar las dinámicas de negociación entre los dirigentes de asociaciones de esas localidades y los agentes civiles y militares del poder público, especialmente durante el Programa de "Pacificación" de Favelas, iniciado en 2008. Argumento que el silenciamiento y el descenso de la crítica de los habitantes son operados a través de la descalificación de esos, y en esa operación la criminalización es un elemento fundamental. Concluyo discutiendo cómo silenciar, disciplinar y criminalizar componen el repertorio del gobierno de los pobres en las periferias urbanas y sus efectos para la democracia.

PALABRA CLAVE: Favela; Asociativismo; Criminalización; Segregación; Militarización. 
E m 2012, quando realizava trabalho de campo' em uma favela da Zona Norte da cidade do Rio de Janeiro, onde tinha sido instalada uma Unidade de Polícia Pacificadora (UPP) no ano anterior, participei de uma reunião na qual estavam presentes representantes militares e civis do projeto de "pacificação", de outros órgãos públicos e das associações de moradores do local. 0 tema da reunião era a coleta de lixo na localidade, primeira ação estatal que seria realizada ali após a entrada da UPP. Nessa oportunidade, presenciei a tentativa desses dirigentes locais de não apenas auxiliar na execução da política específica em tela, mas de discutir o sentido do programa de "pacificação", as possibilidades concretas de fim do "cerco" a que os moradores estavam submetidos pelos grupos de traficantes varejistas de drogas e a necessidade de execução de muitas outras politicas públicas, como o saneamento. Contudo, essas tentativas de alargar o escopo da conversa foram impedidas pelos agentes públicos que estavam organizando a reunião, com a justificativa de que aquele não era o foco no momento.

Um dos presidentes de associação de moradores presente fez então uma fala dura, acusando o programa das UPPs de ser apenas uma fachada, ineficiente, pois ainda permaneciam na favela pessoas ligadas à quadrilha de traficante de drogas local, não apenas comercializando drogas, mas também ameaçando moradores. Disse ainda que ele mesmo, por ser gestor de um serviço público local, tinha sido coagido por esses traficantes a empregar alguns deles e seus parentes no serviço e que os policiais da UPP nada tinham feito para protegê-lo dessa ameaça. A denúncia foi ouvida com constrangimento pelos presentes, inclusive por outros representantes de associações, e, logo em seguida, a reunião foi encerrada. Alguns meses depois, fui informada por interlocutores do campo que esse presidente tinha "desaparecido" da localidade e agora era foragido, procurado pela Polícia Civil, inclusive com recompensa para quem fornecesse informações sobre ele ao Serviço do Disque-Denúncia. Dois anos depois, os jornais anunciaram sua prisão por tráfico e associação para o tráfico de drogas. Segundo a matéria de jornal, os policiais civis que realizaram a prisão disseram ainda que ele utilizava a sede da associação para o comércio de drogas, que empregava traficantes e seus familiares em um programa da prefeitura e "induzia moradores contra a UPP da comunidade" 2.

Nessa mesma favela, ainda em 2012, um comerciante local, presidente da Associação Comercial da localidade, foi assassinado. A entidade que ele presidia tinha sido criada após a instalação da UPP e com o apoio do comandante desta. Esse comerciante teria sido apresentado em diversas ocasiões públicas pelo comandante da UPP como uma nova liderança local, sem relação com os comerciantes de drogas que ali atuavam. Ele teria ainda protagonizado diversos eventos que celebravam a aproximação dos moradores com a polícia "pacificadora", como um casamento "comunitário", com festas públicas organizadas pela associação comercial com o apoio da UPP. Segundo os moradores ouvidos por Sousa (2017), ele teria sido 
assassinado por traficantes de drogas porque era "amigo da UPP" 3 . Após seu assassinato, foi criada uma medalha com seu nome, que o comandante da UPP local concedia aos policiais "que se destacassem na promoção de projetos e iniciativas que vão ao encontro da consolidação da paz e da 'pacificação'" (Sousa, 2017: 75).

Este longo relato de campo introduz a questão que busquei discutir neste artigo: a criminalização de lideranças comunitárias de favelas do Rio de Janeiro, no contexto do Programa de Pacificação que se iniciou em 2008, atingiu 38 favelas cariocas e hoje encontra-se em estágio de extinção gradual. ${ }^{4}$ Essa política consistiu em um conjunto de iniciativas estatais, com o apoio de entes privados, que tinha por objetivo inicial "levar a paz" e "recuperar a soberania do estado" às favelas do Rio de Janeiro (nos termos do discurso oficial), classificadas, nessa lógica, como territórios sem a presença estatal, ${ }^{5}$ Sua ação mais concreta, contudo, foi a instalação de bases para atuação local chamadas de UPPs (Unidades de Polícia Pacificadora), com a presença ostensiva e permanente de policiais militares. As UPPs também prometiam uma nova forma de policiamento, baseada no policiamento comunitário.

Quando foi iniciado, o programa das UPPs despertou grande interesse por parte dos cidadãos do Rio de Janeiro, já que o problema da violência urbana sempre foi um tema "quente" no estado, conformando, inclusive, um enquadramento discursivo-prático (ou uma gramática, como indica Machado da Silva, 2010) que localiza pessoas e territórios dentro de uma certa hierarquia social e, no limite, define quem tem e quem não tem certos direitos. Enquanto a maioria dos moradores da cidade formal (ou do "asfalto", como dizem os cariocas) viram com esperanças a proposta inovadora de ação policial, os moradores de favelas oscilaram entre receber com esperança o programa, duvidar da real intenção dos governantes e silenciar com medo de represálias.

Para pesquisadores da área de estudos urbanos, criminalidade e policiamento, o tema da UPP tornou-se uma agenda obrigatória de pesquisa. Dessa forma, coordenei e participei de diversos projetos de pesquisa que buscavam identificar o que havia de novidade nas UPPs e que efeitos elas teriam sobre a vida dos favelados e de todos os moradores da cidade e do estado. Meu foco de interesse foi os efeitos das UPPs sobre o tecido associativo das favelas, considerando que, em pesquisas anteriores (Silva; Rocha, 2008; Rocha, 2008; 2013), concluí que a contiguidade com os traficantes varejistas de drogas representava um impedimento para a ação coletiva dos moradores dessas localidades. Assim, pelo menos enquanto hipótese, as UPPs representariam a possibilidade de reconfiguração de um tecido associativo comunitário esgarçado pelo cerco imposto pela repressão policial de um lado e a submissão ao tráfico de drogas de outro. No entanto, observamos após mais de seis anos de pesquisa que o "legado" 
do projeto de "pacificação" foi a disseminação de um dispositivo securitário, que chamamos de militarização (Leite et al, 2018), em que o governo das populações moradoras de favelas é exercido (por instituições estatais e paraestatais) através de procedimentos de disciplinarização, conversão moral, vigilância, silenciamento, criminalização, repressão e extermínio. E que, portanto, a "pacificação" não potencializou a "tomada de voz" (Freire, 2008) pelos moradores de favelas no espaço público, mas, sim, seu controle e contenção.

Dessa forma, e a partir das minhas inquietações de pesquisa, argumento neste artigo que a militarização como elemento ordenador da vida social teve como efeito o aumento do silenciamento dos moradores de favelas a partir da criminalização e da desqualificação de suas lideranças. Cabe ressaltar que o momento atual de "crise" das UPPs não significa que esse efeito estaria se diluindo; pelo contrário, afirmo que é fundamental analisar o projeto não como um "fracasso", 6 mas compreender que efeitos produziu e o que permanece após essa experiência. Acredito que esses resultados permaneçam, e é o que pretendo discutir ao final deste artigo.

\section{Do "CONTROle negociado" AO "CERCO"}

ocal de moradia de um a cada cinco habitantes da cidade do Rio de Janeiro (segundo o IBGE,
Censo 2010), as favelas estão presentes no cenário urbano há mais de cem anos e despertam, junto com seus moradores, repulsa e atração. As pesquisas sobre essas localidades, sua população, seus hábitos, valores e formas de organização estiveram muitas vezes orientadas por um principio reformador, como bem demonstrou Valladares (2005). No campo dos estudos sobre associativismo em favelas não foi diferente: preocupações com a "autonomia" versus a "cooptação" dessas organizações frente a governos e partidos; com o classismo versus o clientelismo de suas lideranças; com a representatividade versus o esvaziamento das entidades; entre outros, foram norte de muitas investigações. Contudo, a relação das organizações coletivas de moradores de favelas com o poder público, os políticos, as organizações supralocais (Leeds; Leeds, 1978) e o próprio movimento mais amplo de favelados variou ao longo de sua história conforme as conjunturas políticas locais e nacionais, e também as dinâmicas internas e específicas de cada uma dessas localidades. ${ }^{7}$ A capacidade dessas associações de fazer exigências, sua autonomia de organização, sua cooperação com políticas estatais, o nível de repressão a suas atividades etc., sempre dependeu de uma correlação de forças que se deu em ambiente altamente desfavorável politicamente para esses grupos sociais. $E$, ainda assim, elas lograram continuar existindo. A esse movimento, que incluiu perdas e danos, Machado da Silva (2002) definiu como controle negociado. ${ }^{8}$

0 surgimento das primeiras associações de moradores de favelas, nos anos 1940, aconteceu em um contexto de reação dos favelados às propostas de remoção das suas casas para 
lugares distantes do centro da cidade. Já no início da década de 1960, para tentar conter 0 seu crescimento, o governo municipal estimulou a formação de diversas associações, que seriam agências estatais dentro das comunidades para "auxiliar o governo na implantação de serviços básicos e na manutenção da ordem interna" (Pandolfi; Grynszpan, 2002: 243). Assim, num curto espaço de tempo, entre 1961 e 1962, o Serfha (Serviço Especial de Recuperação de Favelas e Habitações Anti-Higiênicas), sob a direção do sociólogo José Arthur Rios, contribuiu para a formação de mais de 75 associações, entre as quais a União Pró-Melhoramentos dos Moradores da Rocinha (Pandolfi; Grynszpan, 2002: 243).

Com o Golpe Militar de 1964, a política de contenção executada pelo governo estadual se radicaliza, com forte repressão às organizações comunitárias e um violento programa de remoção. De acordo com Valladares (1978), entre 1962 e 1973, mais de 140 mil favelados foram removidos de forma violenta de suas casas. Segundo Pestana (2018), o aprofundamento do programa de remoções se deveu a fortes interesses relacionados aos imóveis, organizados em torno de associações de agentes imobiliários com grande influência no governo (antes e depois da instalação da ditadura empresarial-militar). Apesar de muitas organizações de favelados terem resistido às remoções, com a força da repressão que sobre elas recaiu - inclusive com a suspeita de incêndios criminosos para forçar a retirada da população - as associações passaram a atuar como representantes do governo dentro das favelas, gerenciando os serviços públicos e evitando o seu crescimento (Burgos, 2003; Pandolfi; Grynszpan, 2002).

No final dos anos 1970, com o processo de redemocratização do país e o (re)surgimento de movimentos sociais, é a bandeira da urbanização que impulsiona a organização coletiva. Esse período ficou conhecido como "política da bica d'água", sendo o clientelismo e as relações pessoais entre lideranças das favelas e políticos (Machado da Silva, 1967 [2011]) a tônica. Segundo Burgos (2003), a inexistência de políticas públicas específicas para esses territórios fez com que as associações de moradores adotassem o clientelismo, rocando benefícios para as localidades por votos (Ibid: 39).

A relação de proximidade entre associações e Governo permaneceu nos anos 1990, institucionalizada como parcerias, e, inclusive, teve sua atuação aumentada nesse campo na gestão municipal de César Maia, especialmente em função do Programa Favela-Bairro, iniciado em 1994. Dentro do Programa, as associações também eram gerentes financiados com recursos públicos, e concentraram cada vez mais poder através da contratação de funcionários e serviços. O Programa Favela-Bairro pulverizou a luta por melhorias, pois cada favela tinha que defender seus interesses separadamente, o que "enfraquece o conjunto das mobilizações e despolitiza as reivindicações, circunscrevendo-as à dimensão administrativa e técnico-financeira na qualidade de pequenos lobbies (...)" (Machado da Silva, 2002: 232). 
A lógica da pulverização permanece desde então, seja através do Programa de Aceleração do Crescimento - chamado de PAC das Comunidades ou das Favelas -, seja através das iniciativas que acompanharam a instalação das Unidades de Polícia Pacificadora. Guardadas as diferenças, o formato continuou sendo a ação localizada, privilegiando algumas favelas em detrimento de outras. As associações de moradores continuaram atuando como parceiras, mas participando como executoras das políticas, e não como copartícipes de sua elaboração. Assim, a relação baseada no controle negociado permaneceu, mas com diminuição da capacidade de negociação das associações de forma mais ampliada. ${ }^{9}$ Ainda assim, cada associação individualmente tentou manter seu status de mediadora do Estado dentro do espaço político de cada favela, porém enfrentando diversos obstáculos, que analiso na próxima sessão.

\section{ORGANIZAÇÃO EM TEMPOS DE “PACIFICAÇÃO”}

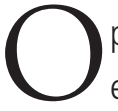

papel de representação dos interesses dos favelados das associações de moradores enfraqueceu-se ao longo do tempo, como demonstramos na sessão anterior. As explicações para tal fenômeno são correlacionadas (e muitas vezes não exclusivas desse tipo de associativismo): fortalecimento da participação institucionalizada em detrimento de movimentos "de base" (Lavalle; Castello; Bichir, 2004), acusações de autoritarismo, corrupção, cumplicidade com grupos criminosos (Leeds, 2003; Zaluar, 2003; Silva; Rocha, 2008; Rocha, 2013), disputa com outros atores sociais pela função da mediação (Rocha, 2013; Carvalho, 2014). Outra dimensão importante, e sobre a qual me detenho aqui, são os constrangimentos à ação coletiva impostos pelas forças armadas ali atuantes: polícias, quadrilhas de traficantes, grupos milicianos (Silva; Rocha, 2008; Rocha, 2013). Há alguns anos, é de conhecimento público que o cerco sobre os moradores de favelas praticado pelas quadrilhas de traficantes se fechou também sobre as associações, causando a morte ou a expulsão de muitos dirigentes de suas casas e territórios de moradia. Uma pesquisa realizada pela Comissão de Direitos Humanos da Assembleia Legislativa do Rio de Janeiro, em 2005, analisou dados sobre 800 dirigentes de associações de moradores de favelas entre 1992 e 2001, e chegou à conclusão de que, nesse período, 300 dirigentes foram expulsos de suas localidades por divergências com traficantes locais e 100 foram assassinados (Leite, 2005: 382). ${ }^{10}$

Conforme apresentei acima, o Programa de Pacificação apresentou-se como uma política para cessar esse cerco dos traficantes de drogas contra os moradores de favelas; contudo, tal programa realizou uma ocupação por forças policiais e militares nesses territórios, o que teve impactos evidentes sobre as organizações locais. Quando as primeiras UPPs foram instaladas 
(entre final de 2008 e início de 2009), havia uma preocupação constante nos discursos oficiais: que a "pacificação" só seria bem-sucedida se o estado levasse também "a cidadania" a esses territórios. Como afirmava o Secretário de Segurança, José Mariano Beltrame, "Só polícia não resolve". ${ }^{11}$ Para tanto, foram articuladas diversas ações estatais e privadas para oferecer serviços que representassem a integração das favelas à cidade formal. Uma dessas iniciativas foi a UPP Social, criada em 2010 e alocada na Secretaria de Estado de Assistência Social e Direitos Humanos, sob direção do economista Ricardo Henriques. Uma das tarefas da UPP Social era realizar fóruns e promover encontros comunitários para que os moradores das favelas agora "pacificadas" pudessem apresentar suas demandas e reivindicações e serem "escutados" (Siqueira et al, 2012: 148). Contudo, também havia a pretensão de firmar compromissos com os moradores a respeito de novas "regras", necessárias à transição para uma regulação da vida social baseada na cidadania como, por exemplo, no que diz respeito às práticas ilegais associadas aos moradores de favelas - como o desvio de energia elétrica, conhecido como "gato".

A questão da adoção de novas regras dentro da legalidade ocupou grande parte dos debates e formulações do programa, e ia ao encontro de outra importante iniciativa ligada ao programa de "pacificação", que era o incentivo à inclusão dos moradores de favelas dentro do mercado formal de consumo. ${ }^{12}$ Em diversas matérias de jornal da época, o tema era abordado, mas de forma a explicitar a dimensão de "missão civilizatória" (Oliveira, 2014) que o programa possuía. Para um gestor da Light entrevistado pelo Jornal Extra, os moradores de favela teriam uma "cultura enraizada de não pagar contas", mas ao começar a pagá-las estariam se "sentindo aptos a reivindicar direitos"13. Já segundo o Coordenador de Polícia Pacificadora Coronel Robson Rodrigues da Silva: "Antes, os moradores de comunidades não eram vistos como cidadãos. Hoje, eles deixaram de ser problema para virar solução. São consumidores e não atuam mais na informalidade" ${ }^{14}$. A "pacificação" seria, portanto, a oportunidade de conversão do favelado em um novo homem (Leite, 2015), cidadão, cumpridor das leis e pagador de suas contas. Mas como participavam do processo de "pacificação" as lideranças locais?

Cunha e Mello (2011) analisaram o caso da "pacificação" na favela Santa Marta, na Zona Sul carioca. Os autores indicam que, além da continuidade de tarefas comuns às associações (como a distribuição de cartas), a associação de moradores local apoiou o programa de "educação do consumidor" oferecido pela empresa de energia elétrica da cidade, cederam a sede da associação para a realização de curso de informática e inclusão digital e foram agentes do projeto de nomeação de ruas da favela, realizado pela Prefeitura. Esse programa, especificamente, visava dar aos moradores do Santa Marta um "endereço", já que a maioria 
dos residentes desta e de outras favelas apenas tem a rua que dá acesso às localidades como endereço oficial. Além disso, tinha a pretensão de servir como primeiro passo para a concessão do "habite-se" aos domicílios, documento que atestaria que as casas estariam dentro dos padrões de construção definidos pela Prefeitura. Contudo, ainda segundo os autores, estimavase que " $(. .$.$) cerca de 80 \%$ das construções da favela Santa Marta terão dificuldade de ter acesso ao habite-se, já que estão fora do gabarito determinado" (Cunha; Mello, 2011: 391). Outro dado importante trazido pelos autores era a reclamação do presidente da associação de moradores local à época, sobre a falta de engajamento dos habitantes com a proposta de regularização do serviço de energia. Para o dirigente, " (. . .) embora a associação de moradores tenha o papel de 'mediar as demandas locais', é fundamental que a população recorra diretamente à concessionária para fazer reclamações e solicitar serviços, agindo agora como 'clientes' e exigindo seus direitos" (Ibid: 393, grifos meus).

No meu trabalho de campo, pude acompanhar a interação entre dirigentes das associações de moradores e os atores estatais civis e militares e não estatais. Trago duas situações aqui.

Quando um programa de urbanização iria iniciar em uma das favelas onde fiz campo, em 2012, participei de uma reunião preparatória à "assembleia"15 de apresentação do programa aos habitantes. Estavam presentes representantes das associações de moradores e organizações locais, da Secretaria Municipal de Habitação (SMH, responsável pelo projeto), de uma tradicional ONG carioca e do gerente local da UPP Social. 0 representante da SMH e a da ONG, que iriam conduzir a "assembleia" nessa reunião, reforçaram que, durante a atividade, o programa seria apresentado, mas que os questionamentos e as reivindicações dos deveriam ser feitos depois, em grupos focais realizados pela ONG, contratada para isso. Quando os representantes das associações tomaram a palavra, afirmaram que os moradores não sabiam "se comportar" em reuniões e, por isso, a dinâmica da "assembleia" teria que ser bem planejada para que intervenções indesejadas não acontecessem. Uma das lideranças chegou a questionar a necessidade de posteriormente escutar os moradores, já que, como representantes, eles mesmos poderiam fornecer à SMH as informações que eles queriam, inclusive sobre as demandas coletivas. Por fim, quando a "assembleia" foi realizada, as pessoas tomaram o microfone e questionaram o fato de o programa ser apenas um levantamento para a realização de um projeto de urbanização quando a expectativa deles era que obras fossem imediatamente iniciadas, inclusive com a construção de residências através do Programa Minha Casa Minha Vida. ${ }^{16}$ A cada resposta negativa dada pelos técnicos da SMH ("os projetos trabalham juntos" e a construção de casas "pode entrar no projeto"; "as obras não começam agora. Agora é o projeto. Obra só ano que vem"), a indignação no auditório onde se realizava a reunião aumentava, expressa pelos sons de desaprovação. Mas, ao final, a reunião terminou 
sem maiores demonstrações de insatisfação. Cabe destacar que, durante todo o evento, os dirigentes das associações de moradores locais ajudaram na contenção e convencimento dos descontentes.

Já em junho de 2013, acompanhei uma das reuniões organizadas pelo comandante da UPP de uma grande favela da Zona Norte. Como essa localidade era palco de diversos tipos de intervenção estatal (como o Programa de Aceleração do Crescimento - PAC para favelas), o auditório estava cheio, tanto de pessoas comuns e representantes de associações de moradores e organizações e movimentos sociais locais quanto de representantes dos diferentes órgãos públicos atuando no local. 0 comandante iniciou a reunião afirmando a importância da "credibilidade" que a Polícia Militar tinha adquirido no local e como ele valorizava a "participação da comunidade" nesse processo. Terminou seu discurso explicando que naquela reunião qualquer tópico poderia ser levantando ("qualquer coisa que aconteça na comunidade é de interesse nosso, não precisa ser apenas sobre Segurança Pública"), pois ele queria ensinar aos moradores "o caminho das pedras" em relação à interlocução com o poder público. Mas quando representantes de uma organização local o questionaram a respeito da forma como os policiais da UPP haviam dispersado uma manifestação contra a violência policial (segundo eles, os policiais teriam atirado contra a multidão que protestava), o comandante os acusou de estarem querendo "tumultuar" a reunião e de serem contrários à "pacificação" (deixando implícito que eles teriam uma preferência pela época em que o traficantes de drogas tinham mais força no local). E encerrou a discussão com o seguinte argumento: como eles poderiam acusar os policias de terem atirado na direção dos moradores se eles não entendiam de tiro nem de balística? ${ }^{17}$

Cabe ressaltar que um dos eixos centrais do programa de "Pacificação" era a proposta de seguir um modelo de policiamento de proximidade e como outros programas específicos para regiões de favelas tinham como cartão de visita a ideia de policiamento comunitário. Modificar a forma como os policiais militares são vistos pela maioria dos favelados (como seus algozes) - inclusive como forma de prevenir a adesão de jovens à carreira criminosa - era uma meta, e, por isso, muitos policiais foram incentivados a aproximarem-se dos moradores através de ações sociais, sobretudo projetos sociais (Teixeira, 2015). ${ }^{18}$ Da mesma forma, além da participação em ações e projetos sociais, o Comando das UPPs determinou, em 2012, que os comandantes das unidades participassem das reuniões comunitárias nos lugares que ocupavam, onde se estabeleceria diálogo com a população ; no local em que ainda não houvesse tido reunião, o comandante deveria organizá-las. Etnografamos diversos encontros comunitários organizados por ou com a presença de policiais militares (Davies, 2014; Rocha; Carvalho; Davies, 2018; Rocha, 2018) e argumentamos como a possibilidade da crítica ao programa de 
"pacificação" estava totalmente rebaixada - ou, nos termos de Boltanski (2013), submetida a uma dominação gestionária. ${ }^{19}$

Nos casos apresentados acima, tentei apresentar algumas das estratégias de silenciamento da crítica realizadas pelos executores da política de "pacificação" em espaços que deveriam ser de diálogo (e questionamento) do programa. Vimos como os dirigentes de associação de moradores tornaram-se coexecutores da implementação da política, abrindo mão de sua função de mediação e representação dos interesses da população - ainda que a execução da política fosse, por vezes, pouco eficaz, como no caso da impossível regularização de residências ou do projeto de urbanização sem obras. Em diversos outros momentos do trabalho de campo, observamos como os questionamentos dos moradores foram classificados como inadequados, porque não estariam sendo apresentados no formato correto ou no momento apropriado. Nessa forma de contenção da crítica, podemos identificar como o programa de "pacificação" opera como um projeto civilizador (Oliveira, 2014) ao representar os moradores de favelas como incapazes de apresentarem suas próprias reivindicações. ${ }^{20}$ Essa desqualificação é claramente expressa, surpreendentemente, pelas palavras de um dirigente favelado: "eles não sabem se comportar em reuniões". No último caso apresentado, vimos como o silenciamento da crítica se dá novamente pela desqualificação dos reclamantes (que não entenderiam de balística), acrescida da acusação de conivência com os traficantes de drogas. Essa acusação era também frequentemente acionada nos espaços que pesquisamos, ainda que, na maior parte das vezes, de forma implícita. É sobre essa forma de silenciamento, a criminalização, que gostaria de me deter na última seção deste artigo.

\section{CRIMINALIZAÇÃO E CERCEAMENTO DA POLÍTICA}

$\mathrm{N}$ o início deste artigo apresentei duas situações de campo e suas repercussões posteriores. No primeiro caso, o presidente de associação de moradores que expressou críticas diretamente ao projeto de "pacificação" não conseguiu nenhuma repercussão para a sua fala - nem mesmo dos outros dirigentes locais presentes. Segundo Sousa (2017), essa mesma liderança era identificada pelos policiais da UPP como pouco confiável e dizia-se que ele era "envolvido" (pertenceria a uma quadrilha de traficantes) (Ibid: 76). Seu pedido de prisão, meses depois do evento descrito, teve como justificativa exatamente os fatos que relatou em sua denúncia: que estaria sendo obrigado a empregar traficantes e seus parentes no programa público que gerenciava. Mas se, em sua denúncia, ele cobrava a responsabilidade do comando da UPP em não oferecer segurança e permitir a atuação das quadrilhas locais, em seu indiciamento ele era responsabilizado individualmente exatamente pelo mesmo motivo, 
mas invertido: não ter sido capaz de impedir a atuação dos traficantes interessados nos recursos que detinha. Assim, mais do que determinar se os rumores sobre seu envolvimento eram verdadeiros ou não, seu indiciamento expressa como são governados os pobres urbanos: 0 encarceramento é sempre uma opção para controlar e conter aquele que não parece estar se comportando de forma adequada. Junto aos atos de silenciar e disciplinar, criminalizar (e, no limite, encarcerar ou exterminar) parece ser uma recorrente estratégia acionada no repertório das técnicas e tecnologias de governo.

Já no segundo caso apresentado, em que o "amigo da UPP" é assassinado, vemos a produção desse favelado que se comporta corretamente, que adere aos valores da missão civilizatória a que está submetido. Ainda segundo Sousa (2017), ele era a liderança local apresentada como legítima e indicada para expressar os interesses dos moradores junto ao poder público (Ibid: 77). No entanto, é importante destacar que seu assassinato demonstra como os corpos dos favelados estão à disposição da aniquilação (Farias, 2008; 2014) mesmo assim.

0 que permite contrastar os dois casos é a forma como a criminalização dos moradores de favelas e suas lideranças, através da acusação de cumplicidade ou conivência com os traficantes de drogas, abre um papel importante na afirmação ou negação de sua legitimidade enquanto representante. Aquele que denunciava a permanência dos traficantes no local apesar da UPP foi criminalizado, e aquele que abertamente defendia a "pacificação" era valorizado enquanto legítimo líder local. A forma como essa legitimidade foi concedida e negada refletia a oposição "amigo da UPP" e "envolvido com o crime".

Assim, perpetua-se o mecanismo de criminalização e deslegitimaç̧ão dos favelados e seus representantes, pela acusação de cúmplices ou criminosos eles mesmos (Machado da Silva, 2004; Machado da Silva; Leite, 2004), e atualiza-se também as formas de limpeza moral (Machado da Silva, 2008; Rocha, 2013) que os moradores têm que acionar para se livrar dessas acusações. Dessa forma, ainda que sob um novo regime de policiamento, que apresenta a "paz", a aproximação entre habitantes locais e policiais e a integração da favela à cidade como pilares, a relação entre favelados e espaço público continua se dando no terreno da condenação moral. Não à toa, logo após a execução da vereadora do Rio de Janeiro Marielle Franco, em março deste ano, fomos bombardeados com informações falsas que a acusavam de ter ligação com quadrilhas de traficantes de drogas, de forma a deslegitimar a afirmação de que sua morte foi um atentado político. A "pacificação" perpetuou o silenciamento dos favelados através da criminalização. E mais uma mulher, negra e favelada teve a sua memória atacada.

Lucas Pedretti (2018) investiga os crimes da ditadura empresarial-militar contra moradores de favelas e suas organizações, argumentando que os favelados - junto com outras 
populações consideradas minoritárias - foram também afetados por essa repressão, mas sua história ainda estaria silenciada. 0 autor discute ainda como as categorias "subversivo" e "comunista" foram plasmadas em lideranças comunitárias da época para justificar sua repressão, detenção e até desaparecimento - mesmo àqueles que afirmavam ter participado da "Marcha da Família com Deus pela Liberdade" em 1964, por exemplo (Ibid: 112). Como demonstram Pedretti (Ibid) e Pestana (2018), a luta contra a remoção das favelas nesse período contrapôs os favelados a interesses muito poderosos, de grupos de capitais do setor imobiliário, e para desmontar a sua resistência, as forças repressivas mobilizaram grandes esforços. Interessa-me pensar, sobretudo, quais as aproximações e afastamentos entre 0 acionamento de categorias como "subversivo" e "comunista" de então e "traficante", "cúmplice" ou "conivente" de hoje para refletir sobre a criminalização dos favelados nesses diferentes contextos.

0 presidente da associação de moradores que foi posteriormente preso, nosso personagem do início deste artigo, concedeu uma entrevista a nossa equipe de pesquisa ainda em 2011. Nela, ele contou de sua juventude como militante do Partido Comunista Brasileiro, seu afastamento posterior, sua eleição meio ao acaso para a associação de moradores, sua esperança que a "pacificação" ajudasse a recuperar o interesse do morador pelas ações coletivas. Em determinado momento, explicando sua esperança de que uma nova polícia tivesse relações menos "contaminadas" com os moradores, ele declarou: "(...) a polícia sempre nos viu como coniventes. Na verdade, nós não fomos coniventes com o trafico e nem com nada de ruim nós fomos conviventes. A palavra certa é convivente. Nós convivemos".

Com o atual contexto que vivemos no Brasil, de aprofundamento da militarização como dispositivo de governo das periferias urbanas, de crescente e reiterado uso de regulamentos de exceção como a Garantia da Lei e da Ordem ${ }^{21}$ para legitimar operações militares de repressão e ocupação territorial, ${ }^{22}$ é preciso investigar e refletir sobre em que condições o controle negociado está sendo exercido - ou se a categoria ainda se aplica. 0 cenário atual é marcado pela intervenção federal na área da segurança pública no Rio de Janeiro, anunciada pelo Presidente Temer em fevereiro de 2018, pela nomeação de um general do Exército como interventor, ${ }^{23}$ pela execução de Marielle Franco... os indícios são muitos. Como afirma Machado da Silva (2002):

Creio que o "controle negociado" é um arranjo que só se sustenta graças à tolerância — e desejo grifar este termo — produzida por aquele abismo de poder entre o que a percepção social classifica como o "asfalto" e a "favela" (Leite, 2001). Por outro lado, é essa mesma tolerância que parece responder pelo sucesso dos disfarces institucionais e simbólicos dessa enorme desigualdade. Acontece que tolerância não se confunde com aceitação, nem com convencimento: de cima para baixo, tolera-se algo que incomoda pouco, e de baixo para cima o que não se tem 
forças para mudar. Neste sentido, não fiz mais do que descrever a institucionalização de uma sociabilidade muito, mas muito mesmo, precária, porque a tolerância não pode ser base para uma relação de alteridade consistente (Ibid: 235).

Talvez o momento atual seja de diminuição da tolerância, da impossibilidade do convencimento, de negação no lugar de aceitação. Que possamos continuar resistindo, apesar de toda a criminalização e repressão, como os favelados têm feito há mais de cem anos.

\section{NOTAS}

1 Os resultados aqui apresentados foram produzidos em diversos projetos de pesquisa, sendo o mais recente "Políticas Públicas, Cidadania e Territórios Periféricos: a permanente (re)construção do estado nas margens do Rio de Janeiro", coordenado por mim e financiado pela Faperj através do edital Jovem Cientista do Nosso Estado 2015. Gostaria de agradecer aos companheiros do CIDADES - Núcleo de Pesquisa Urbana, com quem divido as análises, as angústias e as esperanças, e à Claudia Trindade e à Emanuelle Araújo, que fizeram parte importante do campo que apresento aqui e iniciaram comigo as primeiras reflexões que hoje apresento.

2 Como a prisão de Mario foi divulgada pela imprensa e qualquer tentativa de evitar expor seu nome e potencialmente contribuir para a sua criminalização foram por mim consideradas insuficientes, coloco o link da matéria: O GLOBO. Ex-presidente da Associação de Moradores do Morro dos Macacos é preso. 26 de Agosto de 2015. Disponível em<https://oglobo.globo.com/rio/ex-presidente-da-associacao-de-moradores-do-morro-dos-macacos-preso-17311798>.

3 Fernando Sousa, em pesquisa realizada na mesma localidade, discutiu o uso dessa categoria pelos policiais militares e pelos moradores como, por um lado, estratégia para reorganizar o tecido associativo local, aproximando os representantes da UPP das lideranças escolhidas por eles como as "corretas", e, por outro lado, como categoria de acusação pela aproximação indevida com as forças de ocupação - e também como forma de ameaça e/ou aviso, como na frase "cuidado, você está muito amigo da UPP". Para maiores informações, ver Sousa, 2017.

4 Sobre o desmonte do Programa de "Pacificação", ver a manchete "Intervenção anuncia o fim de 12 UPPs e mudanças em outras sete unidades" do jornal 0 Globo, de 26 de abril de 2018. Disponível em: <https:// oglobo.globo.com/rio/intervencao-anuncia-fim-de-12-upps-mudancas-em-outras-sete-unidades-22631936>; e «Governo inicia fechamento de metade UPPs nas comunidades do Rio». AFP, 27 de Abril de 2018. Disponível em: $<$ https://exame.abril.com.br/mundo/governo-inicia-fechamento-de-metade-upps-nas-comunidades-do-rio/>.

5 Uma bibliografia, hoje considerável, discute há algum tempo como a representação das favelas como lugares "sem presença estatal" é parte da engrenagem de segregação e criminalização dessas localidades e de seus habitantes. Sobre isso, ver, entre outros: Machado da Silva, 2008; Leite, 2018; Carvalho, 2014.

6 Pensar o fracasso como oportunidade para a compreensão dos efeitos de projetos e políticas é a proposta de diversos autores, mas utilizo aqui, sobretudo, a sugestão de Ferguson (2009).

7 Conforme demonstrou Doimo (1995), os movimentos sociais urbanos no Brasil, especialmente no período da abertura política pós-ditadura de 1964, são caracterizados por uma dupla face: a expressivo-disruptiva e a integrativo-corporativa (Doimo, 1995: 222). Essa dualidade, portanto, é característica dessas organizações e não específica dos movimentos de moradores de favelas. 
8 Em seu artigo, 0 autor busca demonstrar como, no momento pré-1964, os moradores de favela foram bem-sucedidos, em termos, em sua luta contra as tentativas de remoção de suas casas. A dimensão da negociação teria sido suspensa, contudo, durante o regime militar, retornando com a abertura e o primeiro Governo Brizola (1983-1987).

90 crescimento da presença de organizações não governamentais nos territórios de favelas - sejam conduzidas por moradores de favela ou não - e a disputa que elas passaram a travar com as associações pelo papel de "falar pelas favelas" também contribuírampara diminuir essa capacidade de negociação. Analiso em detalhes essa disputa em Rocha, 2013.

10 Leite aponta que as expulsões de dirigentes, e mesmo de moradores não envolvidos na política local, eram tão frequentes quanto invisiveis para a sociedade em geral, muitas vezes não sendo percebidas mesmo como uma modalidade de violência praticada pelos traficantes de drogas. Com o aumento de casos, no entanto, a categoria de "refugiados do tráfico" passou a ser utilizada nos meios de comunicação (Leite, 2005: 381-383).

11 "Entrar na favela e ficar não vale somente para a polícia. A polícia não vai resolver. Tem que o Estado vir atrás". Cf. Estadão On Line. "Só UPP não resolve, 08/11/2010. Disponível em: <http://www.estadao.com.br/ noticias/geral, beltrame-so-upp-nao-resolve-estado-tem-de-agir-junto,636814,0.htm>. Acessado em: $<02$ de Outubro de 2018>.

12 embricamento entre "pacificação" e "mercantilização" é outra fundamental dimensão do dispositivo da militarização, mas não é possível abordar o tema no escopo deste artigo. Sobre o tema, ver Ost; Fleury, 2013; Barbosa, 2012; Leite et al, 2018; Rocha; Carvalho, 2018; entre outros.

13 "Compromisso..., com a legalidade", Jornal Extra, 14 de fevereiro de 2010.

14 "Duas empresas prestes a doar 1,3 milhão", 0 Globo, 30 de Janeiro de 2011.

15 Coloquei o termo assembleia entre aspas porque, como veremos a seguir, tratava-se de evento em que os moradores não poderiam falar, apenas ouvir, o que mais se assemelha a uma palestra que a uma assembleia.

160 programa Minha Casa, Minha Vida financia a construção e a compra de habitações para diferentes faixas de renda. Sobre o tema, ver Conceição, 2018.

17 Também analisei essa mesma situação em Rocha, 2018.

18 A aproximação entre moradores de favelas e policiais militares, através da participação em projetos sociais, é uma situação social atravessada por diversas ambivalências e conflitos que não posso explorar aqui. Sobre o assunto, ver o excelente trabalho de Teixeira, 2013.

19 Para o autor, esse tipo de dominação (diferente da dominação ideológica ou pelo terror) sustenta-se na legitimidade que passam a ter na esfera pública e política certas técnicas de gerenciamento e gestão, transplantadas das grandes empresas. Somadas à primazia do economicismo e dos discursos técnico-científicos como formas de justificação às práticas de governo, com essas técnicas, busca-se enfrentar, institucionalmente, as críticas e, assim, rebaixar as possibilidades de reivindicação dos dominados (Boltanski, 2013).

20 A representação dos favelados como incapazes de se organizar politicamente é antiga (Perlman, 1977; Valladares, 1978) e compõe o estigma que recai sobre os pobres como incivilizados em diversos outros contextos nacionais, como argumentam Das \& Poole (2004).

21 Acionadas apenas com ordem expressa da Presidência da República, as operações GLO devem ocorrer apenas, segundo o site do Ministério da Defesa, "nos casos em que há o esgotamento das forças tradicionais 
de segurança pública, em graves situações de perturbação da ordem". Ainda segundo o site do Ministério da Defesa: "Reguladas pela Constituição Federal, em seu artigo 142, pela Lei Complementar 97, de 1999, e pelo Decreto 3.897, de 2001, as operações de GLO concedem provisoriamente aos militares a faculdade de atuar com poder de polícia até o restabelecimento da normalidade. Nessas ações, as Forças Armadas agem de forma episódica, em área restrita e por tempo limitado, com o objetivo de preservar a ordem pública, a integridade da população e garantir o funcionamento regular das instituições", Cf. Ministério da Defesa, 2018, disponível em <https://www.defesa.gov.br/exercicios-e-operacoes/garantia-da-lei-e-da-ordem>.

22 A Garantia da Lei e da Ordem foi acionada durante as Ocupações Militares no Alemão (2010) e na Maré (2014-2015). Importante ressaltar ainda que militares que atentarem contra a vida de civis sob a GLO serão julgados apenas em tribunais militares, em função da lei sancionada por Temer em agosto de 2017, que modifica a lei de 1996, que garantia que tais acusações seriam julgadas por Tribunais de Júri da Justiça comum.

23 A primeira vez que o Rio de Janeiro sofreu uma intervenção federal foi em 1937, durante o Estado Novo. A manobra se repetiu em 1966, durante a ditadura empresarial-militar. A intervenção mais recente, contudo, foi em 1994, quando o então governador Nilo Batista assinou "um convênio que subordinava a estrutura policial do estado ao Comando Militar do Leste" . Disponível em: <https://acervo.oglobo.globo.com/em-destaque/ rio-de-janeiro-tem-historico-de-intervencao-federal-desde-estado-novo-22405671\#ixzz5TGRrq2rd>. Acessado em: $<05$ de Outubro de 2018>.

\section{REFERÊNCIAS BIBLIOGRÁFICAS}

BARBOSA, Antonio Rafael. Considerações Introdutórias sobre territorialidade e mercado na conformação das Unidades de Polícia Pacificadora no Rio de Janeiro. Revista Brasileira de Segurança Pública, São Paulo, v. 6, n. 2, p. 256-265, ago.-set. 2012.

BOLTANSKI, Luc. Sociologia da crítica, instituiç̃̃es e o novo modo de dominação gestionária. Sociologia \& Antropologia, Rio de Janeiro, v. 3, n. 6, p. 441-463, 2013.

BURGOS, Marcelo Baumann. Dos parques proletários ao Favela-Bairro: as políticas públicas nas favelas do Rio de Janeiro. In: ZALUAR, Alba; ALVITO, Marcos (Org.). Um século de favela. Rio de Janeiro: Ed. FGV, p. 25-60, 2003.

CARVALHO, Monique Batista. Os dilemas da "pacificação": práticas de controle e disciplinarização na "gestão da paz" em uma favela do Rio de Janeiro. 2014. Tese (Doutorado em Ciências Sociais) - Programa de Pós-Graduação em Ciências Sociais, Universidade do Estado do Rio de Janeiro, Rio de Janeiro, 2014.

CONCEIÇÃO, Wellington da Silva. "Sossega, moleque, agora você mora em condomínio": segregaÇão, gestão e resistências nas novas políticas de moradia popular no Rio de Janeiro. Curitiba: Appiris Editora, 2018.

CUNHA, Neiva Vieira \& MELLO, Marco Antonio Silva. Novos Conflitos na Cidade: A UPP e o Processo de Urbanização na Favela. Dilemas: Revista de Estudos de Conflito e Controle Social, vo. 4, n.3, pp. 371-401, 2011.

DAS, Veena; POOLE, Deborah. Anthropology in the margins of the state. Santa Fe: School of American Research Press, 2004.

DAVIES, Frank Andrew. Rituais de "pacificação": uma análise das reuniões organizadas pelos comandos das UPPs. Revista Brasileira de Segurança Pública, São Paulo, v. 8, n. 1, p. 24-46, 2014. 
DOIMO, Ana Maria. A vez e a voz do popular: movimentos sociais e participação política no Brasil pós-70. Rio de Janeiro: Relume-Dumará, 1995.

FARIAS, Juliana. Quando a exceção vira regra: os favelados como população "matável" e sua luta por sobrevivência. Teoria \& Sociedade, Belo Horizonte, v. 15, n. 2, p. 138-171, 2008.

Governo de mortes: uma etnografia da gestão de populações de favelas no Rio de Janeiro. 2014. Tese (Doutorado em Sociologia) - Universidade Federal do Rio de Janeiro, Rio de Janeiro, 2014.

FERGUSON, James. The anti-politics machine. In: SHARMA, Aradhana; GUPTA, Akhil. The anthropology of the state: a reader. Hoboken: John Wiley \& Sons, p. 270-286, 2009.

FREIRE, Jussara. "Elevar a voz em uma ordem violenta: a indignação colocada à prova pelo silêncio". In: MACHADO DA SILVA, Luiz Antonio (Org.). Vida sob o cerco: violência e rotina nas favelas no Rio de Janeiro. Rio de Janeiro: Faperj/Nova Frontera, 2008.

INSTITUTO BRASILEIRO DE GEOGRAFIA E ESTATÍSTICA. Censo 2010. Disponível em: <https://ww2.ibge.gov. br/home/estatistica/populacao/censo2010/default.shtm>. Acessado em 26 de outubro de 2018.

LAVALLE, Adrián Gurza; CASTELLO, Graziela Luz; BICHIR, Renata Mirándola. Artigo: quando novos atores saem de cena - continuidades e mudanças na centralidade dos movimentos sociais. Política \& Sociedade, Florianópolis, v. 3, n. 5, p. 37-55, 2004.

LEEDS, Anthony; LEEDS, Elizabeth. Sociologia do Brasil urbano. Rio de Janeiro: Zahar Editores, 1978.

LEEDS, Elizabeth. Cocaína e poderes paralelos na periferia urbana brasileira: ameaças à democratização em nível local. In: ZALUAR, Alba; ALVITO, Marcos (Org.). Um século de favela. Rio de Janeiro: Ed. FGV, 2003.

LEITE, Márcia Pereira. Miedo y representación comunitaria en las favelas de Rio de Janeiro: los invisibles exilados de la violencia. In: REGUILO, R.; GODOY, M. A. (Org.). Ciudades translocales: espacios, flujo, representación: perspectivas desde las Américas. Guadalajara: Editorial ITESO; New York: Social Sciences Research Council, 2005. p. 365-392.

.De territórios da pobreza a territórios de negócios: dispositivos de gestão das favelas em contexto de "pacificação". In: BIRMAN, Patricia et al. Dispositivos urbanos e trama dos viventes: ordens e resistências. Rio de Janeiro: Faperj: Ed. FGV, 2015. p. 377-401.

LEITE, Márcia Pereira; ROCHA, Lia de Mattos, FARIAS, Juliana \& CARVALHO, Monique Batista de (Org.). Militarização no Rio de Janeiro: da "pacificação" à intervenção. Rio de Janeiro: Mórula, 2018. 324 p.

MACHADO DA SILVA, Luiz Antonio. A política na favela. Dilemas: Revista de Estudos de Conflito e Controle Social, Rio de Janeiro, v. 4, n. 4, p. 699-716, 1967 [2011].

. A continuidade do "problema da favela". In: LIPPI, Lucia (Org.). Cidade: história e desafios. Rio de Janeiro: Ed. FGV, 2002. p. 220-237.

Sociabilidade violenta: uma dificuldade a mais para a ação coletiva nas favelas. In: Rio: a democracia vista de baixo. Rio de Janeiro: IBASE, p. 33-44, 2004.

"Violência urbana", segurança pública e favelas: o caso do Rio de Janeiro atual. Caderno CRH, Salvador, v. 23, n. 59, p. 283-300, 2010. 
MACHADO DA SILVA, Luiz Antonio; LEITE, Márcia Pereira. Favelas e democracia: temas e problemas da ação coletiva nas favelas cariocas. In: Rio: a democracia vista de baixo. Rio de Janeiro: IBASE, p. 61-78, 2004.

OLIVEIRA, João Pacheco de. Pacificação e tutela militar na gestão de populações e territórios. Mana, Rio de Janeiro, v. 20, n. 1, p. 125-161, 2014.

OST, Sabrina; FLEURY, Sônia. 0 mercado sobe ao morro: a cidadania desce? Efeitos Socioeconômicos da pacificação no Santa Marta. Dados: Revista de Ciências Sociais, Rio de Janeiro, v. 56, n.3, p. 635-671, 2013.

PANDOLFI, Dulce; GRYNSZPAN, Mário. Poder público e favelas: uma relação delicada. In: LIPPI, Lucia (Org.). Cidade: história e desafios. Rio de Janeiro: Ed. FGV, 2002. p. 238-255.

PEDRETTI, Lucas. Ditadura, remoções forçadas e a luta dos moradores de favelas da Guanabara (1963-1973). Clepsidra: Revista Interdisciplinaria de Estudios sobre Memória, v. 5, n. 10, p. 94-115, 2018.

PERLMAN, Janice E. O mito da marginalidade: favelas e política no Rio de Janeiro. São Paulo: Paz e Terra, 1977.

PESTANA, Marcos Marques. Complexificação da sociedade civil e ampliação seletiva do Estado brasileiro: 0 caso do programa de remoções de favelas no Rio de Janeiro, 1957-1973. 2018. Tese (Doutorado em História) - Universidade Federal Fluminense, Niterói, 2018.

ROCHA, Lia de Mattos. "Uma favela sem tráfico?" Os limites da ação e da opressão do tráfico. In: MACHADO DA SILVA, Luiz Antonio (Org.). Vida sob cerco: violência e rotina nas favelas do Rio de Janeiro. Rio de Janeiro, Faperj: Nova Fronteira, 2008.

"Uma favela diferente das outras?" Rotina, silenciamento e ação coletiva na favela do Pereirão, Rio de Janeiro. Rio de Janeiro: Faperj: Ed. Quartet, 2013. 328 p.

Democracia e militarização no Rio de Janeiro: "pacificação", intervenção e seus efeitos no espaço público. In: LEITE, Márcia Pereira et al (Org.). Militarização no Rio de Janeiro: da "pacificação" à intervenção. Rio de Janeiro: Mórula, 2018. p. 223-239.

ROCHA, Lia de Mattos; CARVALHO, Monique Batista. Da "cidade integrada" à "favela como oportunidade": empreendedorismo, política e "pacificação" no Rio de Janeiro. Campinas: Caderno Metrópole. No prelo. 2018.

ROCHA, Lia de Mattos; CARVALHO, Monique Batista \& DAVIES, Frank Andrew. Crítica e controle social nas margens da cidade: etnografia de espaços de participação em favelas "pacificadas" do Rio de Janeiro. r@u Revista de Antropologia Social dos Alunos do PPGAS-UFSCar, Volume 10, número 1, jan./jun. 2018, p. 216-237.

SILVA, Itamar; ROCHA, Lia de Mattos. Associações de moradores de favelas e seus dirigentes: o discurso e a ação como reversos do medo. In: JUSTIÇA GLOBAL. Segurança, tráfico e milíicias. 1. ed. Rio de Janeiro: Fundação Heinrich Boll, , 2008. v. 1, p. 37-47.

SIQUEIRA, Raíza; SILVA, Hélio R. S.; MENDONÇA, Tássia; STROZEMBERG, Pedro; SENTO-SÉ, João Trajano; LANDIM, Leilah; GUARIENTO, Suellen. Entrevistas. In: RODRIGUES, André, SIQUEIRA, Raíza \& LISSOVISKY, Maurício (org.). Unidade de Polícia Pacificadora: debates e reflexões. Comunicações do ISER, Dezembro de 2012, pp. 134-157.

SOUSA, Fernando Carlos de. "Ajude o BOPE a ajudar você": uma etnografia sobre a gestão da proximidade e da participação política dos moradores de favelas no contexto de pacificação. 2017. Dissertação (Mestrado 
em Ciências Sociais) - Programa de Pós-Graduação em Ciências Sociais, Universidade do Estado do Rio de Janeiro, Rio de Janeiro, 2017.

TEIXEIRA, Cesar Pinheiro. A teia do bandido: um estudo sociológico sobre bandidos, policiais, evangélicos e agentes sociais. Tese (Doutorado em Sociologia e Antropologia) - Programa de Pós-Graduação em Sociologia e Antropologia, Universidade Federal do Rio de Janeiro, 2013.

0 'policial social': algumas observações sobre o engajamento de policiais militares em projetos sociais no contexto de favelas ocupadas por UPPs. Dilemas: Revista de Estudos de Conflito e Controle Social, Rio de Janeiro, v. 8, n. 1, p. 77-96, 2015.

VALLADARES, Lícia do Prado. Passa-se uma casa: análise do programa de remoção de favelas do Rio de Janeiro. Rio de Janeiro: Zahar Editores, 1978.

A invenção da favela: do mito de origem a favela.com. Rio de Janeiro: Ed. FGV, 2005.

ZALUAR, Alba. Crime, medo e política. In: ZALUAR, Alba; ALVITO, Marcos (Org.). Um século de favela. Rio de Janeiro: Ed. FGV, 2003. 
